\title{
ATUAL SITUAÇÃO DO CURSO DE ENGENHARIA METALÚRGICA NO BRASIL
}

\author{
Igor Jurandir Ubaldo Viana Pereira - igorjurandir@gmail.com \\ Universidade Federal de Ouro Preto, Departamento de Engenharia Metalúrgica \\ Campus Morro do Cruzeiro, UFOP \\ 35400-000 - Ouro Preto - MG
}

Arthur Cançado Schuttenberg - schuttenberg.arthur@gmail.com

Carlos Alberto Pereira-pereiraufop@gmail.com

\begin{abstract}
Resumo: O presente trabalho realizou um estudo da atual situação do curso de Engenharia Metalúrgica no Brasil a partir de dados disponíveis pelo cadastro e-MEC. Os parâmetros analisados durante o trabalho foram: disposição dos cursos no território nacional; número de vagas; carga horária; história dos cursos; situação de funcionamento e índices de avaliações do MEC. A partir dessas análises, foi possível identificar a real situação dos cursos de Engenharia Metalúrgica no Brasil, constatando que estes podem ser otimizados. Entre outras conclusões, destacam-se a relação entre a localização das instituições e a demanda de profissionais disponíveis para suprir as necessidades do curso; o equilíbrio entre o número de instituições públicas e privadas; a superioridade dos cursos públicos em relação aos privados nas avaliações do Enade e a crescente média das instituições privadas no exame ao longo dos anos.
\end{abstract}

Palavras-chave: Engenharia Metalúrgica. Cursos. Polos Metalúrgicos.

\section{INTRODUÇÃO}

A metalurgia do ouro e do ferro foram os primeiros marcos da metalurgia no Brasil. Há indícios de que o início da metalurgia do ferro no Brasil ocorreu por meio dos conhecimentos africanos de extração de ferro (LANDGRAF, TSCHIPTSCHIN e GOLDENSTEIN, 1994). As primeiras fábricas fundadas no Brasil eram situadas em Gaspar Soares (hoje Morro do Pilar MG) e em Iperó - SP nos anos de 1809 e 1810, respectivamente, porém ambas as empresas demoraram anos para conseguirem produzir os seus produtos (MARCOLIN, 2010).

A criação do curso de Engenharia Metalúrgica no Brasil foi um marco importante para o progresso das empresas siderúrgicas do país. A primeira instituição a formar engenheiros metalúrgicos no Brasil foi a Escola de Minas de Ouro Preto, inaugurada em 1876 por Claude Henri Gorceix, e idealizada por Dom Pedro II. Em 1969, a Escola de Minas de Ouro Preto foi incorporada à Universidade Federal de Ouro Preto pelo Decreto-Lei ${ }^{\circ} 778$ (ESCOLA DE MINAS, 2018).

Buscando expandir a industrialização do país, no início da década de 1930, foi verificada a necessidade do desenvolvimento da siderurgia. Os estados de São Paulo e Minas Gerais eram os estados com maior quantidade de pequenas metalúrgicas, porém essas empresas não eram suficientes para suprir a demanda do país (BARROS, 2015). Com a expansão das empresas siderúrgicas no Brasil, a demanda por profissionais qualificados cresceu significativamente, resultando em novas instituições de ensino em todo o país. Atualmente, 36 instituições estão 
regulamentadas pelo Ministério da Educação (MEC) para operação do curso de Engenharia Metalúrgica.

Os cursos de Engenharia Metalúrgica disponíveis no Brasil estão em estado de alerta. Fatores como evasão e qualidade dos cursos necessitam ser trabalhados a fim de garantir uma educação de melhor qualidade. Portanto, esta pesquisa justifica-se pelo desejo de otimizar os cursos de Engenharia Metalúrgica no país, permitindo que haja a redução da taxa de evasão e aprimoramento da qualidade do ensino em instituições nacionais.

O presente trabalho tem como objetivo realizar um estudo da atual situação do curso de Engenharia Metalúrgica no Brasil. A análise da disposição dos cursos no território nacional, número de vagas, carga horária história dos cursos, situação de funcionamento e índices de avaliações do MEC são fatores que podem auxiliar no gerenciamento e na melhoria da qualidade dos cursos no Brasil.

\section{METODOLOGIA}

Os dados deste trabalho foram obtidos com o apoio dos arquivos do portal e-MEC.

Os dados coletados foram utilizados para plotar gráficos comparativos através do software Excel e, a partir desses gráficos, foram desenvolvidos argumentos baseados em trabalhos previamente realizados que explicassem cada evento observado.

\section{RESULTADOS E DISCUSSÃO}

\subsection{Cursos de Engenharia Metalúrgica no Brasil}

O cadastro e-MEC, regulamentado pela Portaria Normativa ${ }^{\circ} 21$, de 21 de dezembro de 2017, informa que o Brasil possui 36 cursos de Engenharia Metalúrgica regulamentados. O país possui 35 cursos presenciais distribuídos em sete estados, sendo eles, Pará, Ceará, Minas Gerais, Espirito Santo, Rio de Janeiro, São Paulo e Rio Grande do Sul, conforme representado na Figura 1. O único curso a distância regulamentado no país está localizado em Sete Lagoas MG, porém suas atividades ainda não foram iniciadas. 
CCOBENCE 2020 (2)

"Os desafios para formar hoje o engenheiro do amanhã"
$\mathrm{Ol} \mathrm{a} \mathrm{O3}$ de dezembro Evento On-line

Figura 1 - Cursos de Engenharia Metalúrgica presenciais e a distância no Brasil

Cursos presenciais

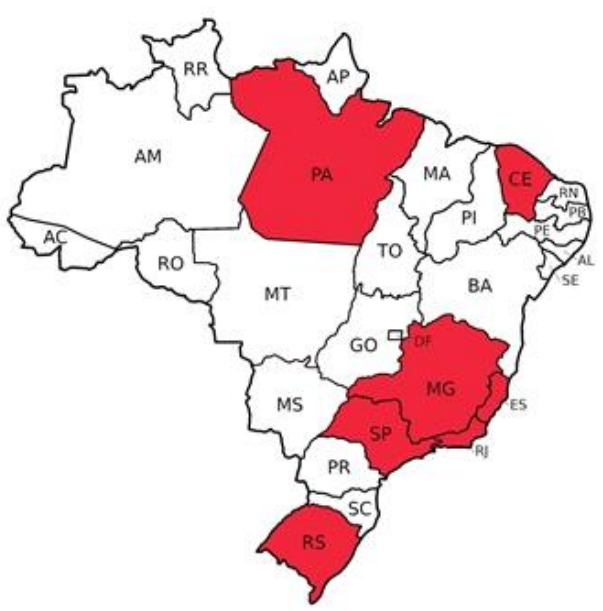

Cursos a distância

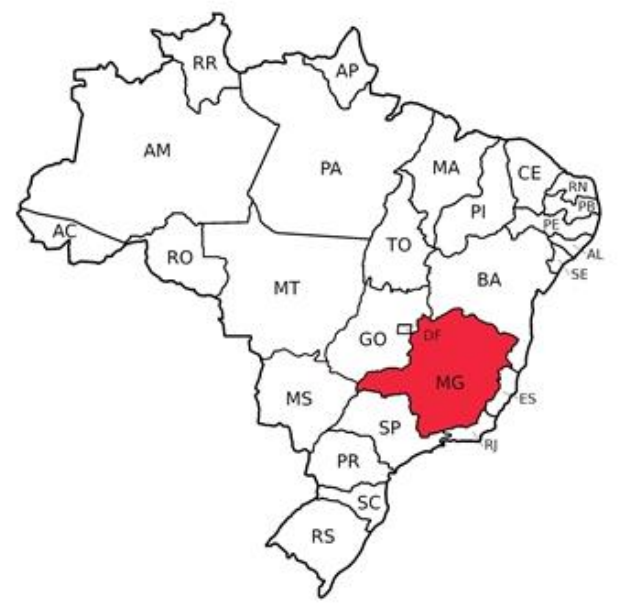

Fonte: Elaborado pelos autores.

O número de instituições disponíveis em cada estado está diretamente relacionado com os polos metalúrgicos do país, os quais estão localizados no Pará e nas regiões centro, sudeste e sul (MOTA, 2009) (SALES , 2006). O Gráfico 1 apresenta a distribuição de cursos de Engenharia Metalúrgica por estado.

Gráfico 1 - Número de instituições que ofertam o curso de Engenharia Metalúrgica por estado

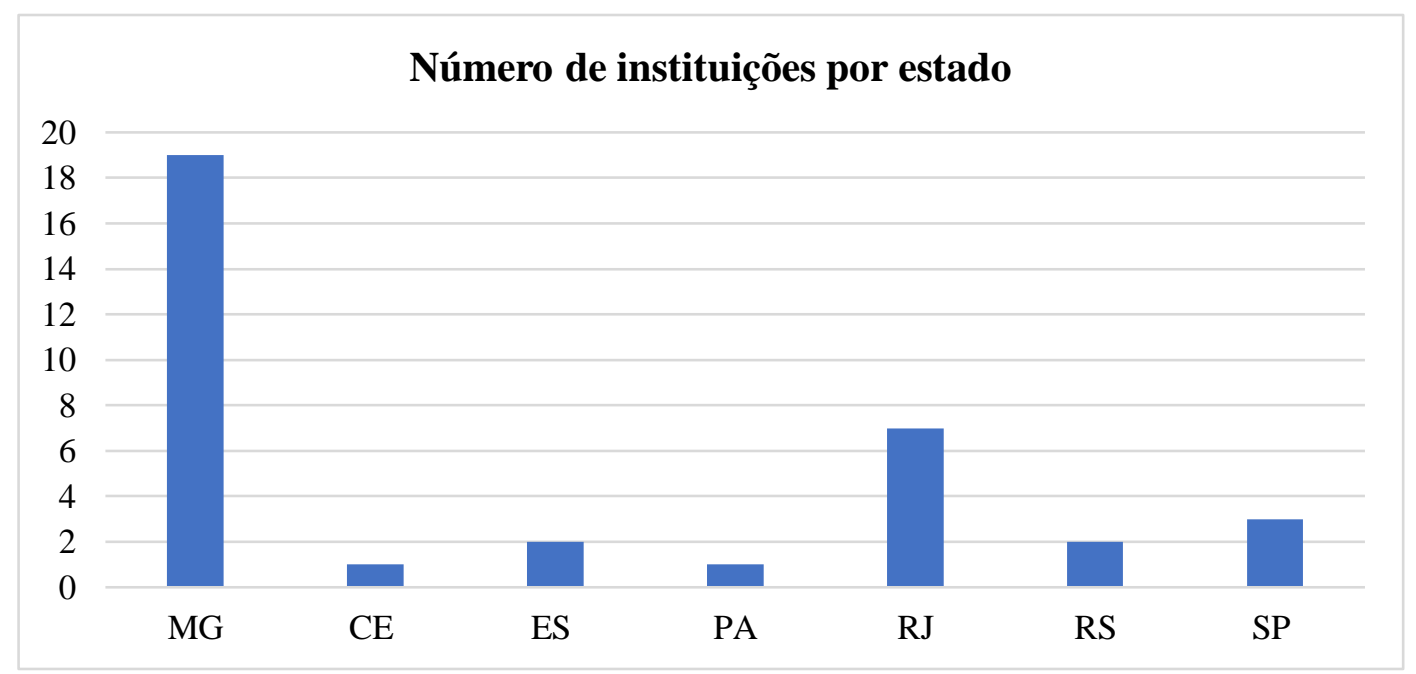

Fonte: Elaborado pelos autores.

É notória a disparidade entre a quantidade de cursos no estado de Minas Gerais em relação aos demais. Isso está relacionado às elevadas produções de minérios e produtos siderúrgicos no estado. Rio de Janeiro e São Paulo são estados que possuem um grande número de indústrias metalúrgicas, justificando a alta demanda de alunos, para o curso. No estado do Pará, apenas uma instituição de ensino oferta o curso de Engenharia Metalúrgica, e boa parte 
da demanda de alunos dessa instituição está relacionada com a Serra de Carajás, região importante na extração de minério de ferro.

\subsection{Vagas nos cursos de Engenharia Metalúrgica}

Os dados referentes ao número de vagas, coletados no portal e-MEC, permitiram concluir que a média nacional de vagas anuais por instituição é de 81,25. A Gráfico 2 apresenta a média de vagas disponibilizadas em cada estado.

Gráfico 2 - Média de vagas anuais nos cursos de Engenharia Metalúrgica por estado

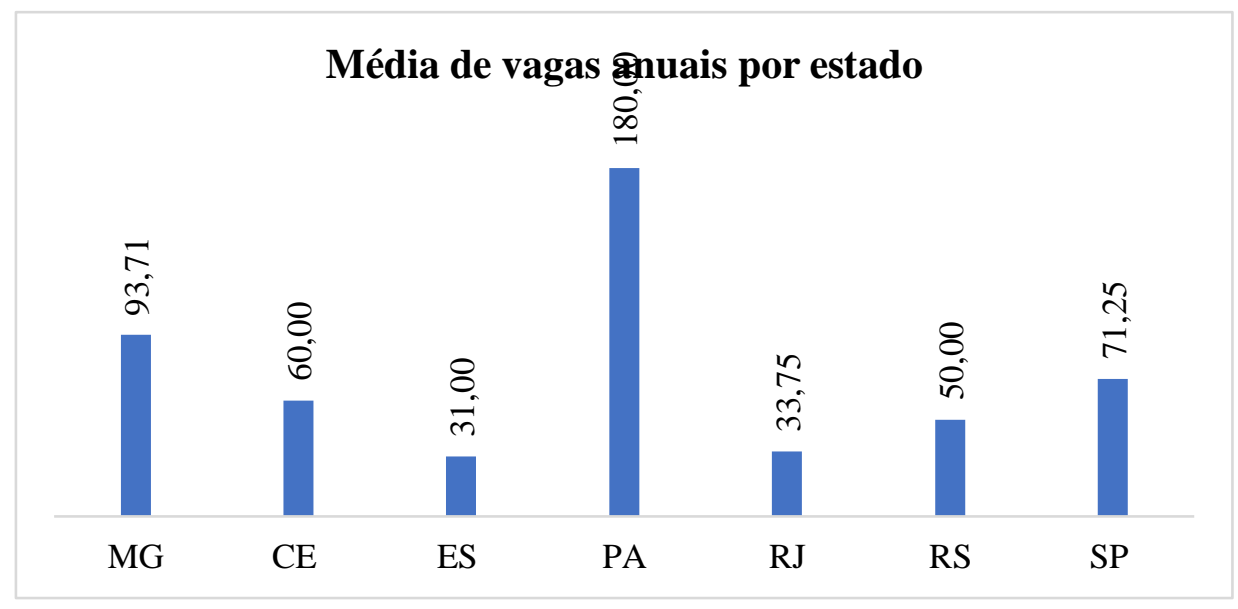

Fonte: Elaborado pelos autores.

A alta média do estado do Pará justifica-se por esse estado possuir apenas uma instituição de ensino que oferece o curso de Engenharia Metalúrgica. Vale destacar que a média de vagas dos cursos por estado está diretamente relacionada à demanda de alunos, que buscam por uma formação profissional para atuar nas indústrias, tornando necessária maior quantidade de vagas disponíveis no estado, como ocorre em Minas Gerais e São Paulo.

A Gráfico 3, a seguir, mostra a quantidade de cursos oferecidos em instituições públicas e privadas no Brasil.

Gráfico 3 - Média de vagas anuais por tipo de instituição 


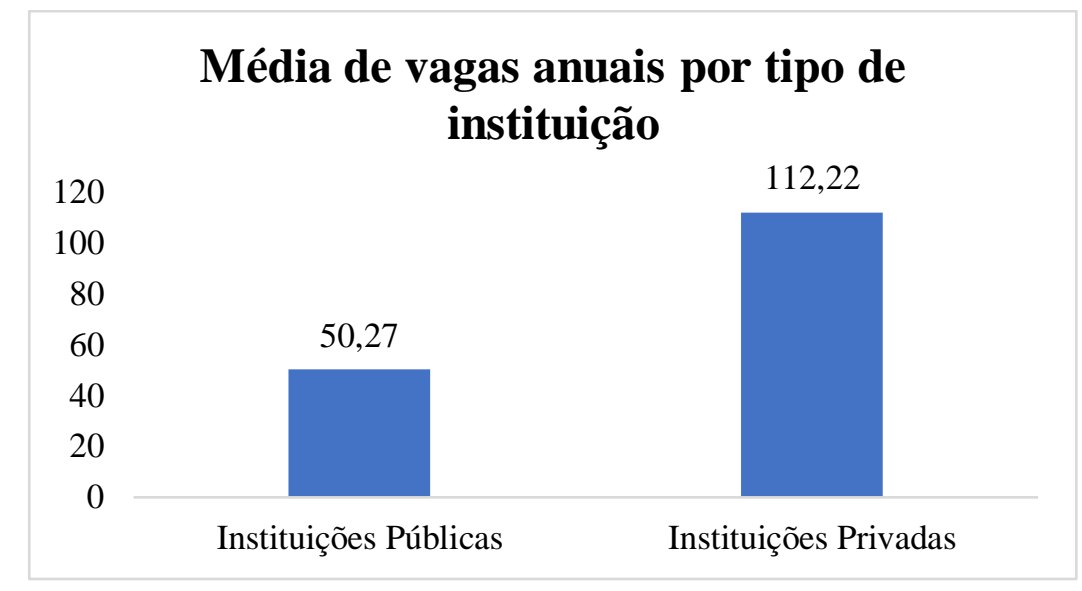

Fonte: Elaborado pelos autores.

A partir da análise da figura acima, é possível concluir que o número de vagas anuais em instituições privadas é superior às vagas disponíveis nas instituições públicas. Esse fato está relacionado à necessidade de as instituições privadas possuírem um alto número de alunos matriculados para manter o curso em funcionamento, conforme citado por Rodacoski e Tozzi (2008).

\subsection{Relação dos cursos públicos e privados}

Dos 36 cursos de Engenharia Metalúrgica disponíveis no país, 18 são de instituições privadas e 18 de instituições públicas. Esse dado relata a dificuldade de manutenção do curso, uma vez que, quando comparado a outros cursos, o número de cursos de engenharia em instituições privadas tende a ser maior que em instituições públicas. Ainda sobre o tema, Rodacoski e Tozzi (2008) dizem que os custos de implantação de laboratórios específicos são extremamente altos. Resultando em um alto custo da mensalidade e fazendo com que o número de ingressantes não atinjam, na média, 50\% do número de vagas ofertadas nas instituições privadas.

Os dados permitem concluir, ainda, que a demanda de alunos para o curso de Engenharia Metalúrgica, tanto nas instituições públicas quanto privadas, é inferior à de outros cursos de engenharia, como Engenharia Civil. Esse fato é justificado pela igualdade do número de cursos pelo tipo de instituição, uma vez que, para as instituições privadas abrirem um curso de Engenharia Metalúrgica, é necessário que haja uma demanda mínima de alunos na região, provando que a demanda de alunos não torna viável a implantação de novos cursos.

\subsection{O fator carga horária como garantia de qualidade}

A carga horária é fundamental para garantir a qualidade dos cursos de Engenharia Metalúrgica. No Brasil, a média total dos cursos é de 3963,67 horas, sendo o de maior carga horária ofertado pela Universidade Estadual do Norte Fluminense Darcy Ribeiro, com 4911 horas necessárias para obter a certificação de engenheiro metalurgista. Por outro lado, a menor carga horária do Brasil é de 3600 horas, essa carga é aplicada em quatro instituições privadas de ensino, e em duas instituições públicas. A Tabla 1 mostra a média das cargas horárias do curso de Engenharia Metalúrgica de instituições públicas e privadas no Brasil. 
Tabela 1 - Média da carga horária (em horas) do curso de

Engenharia Metalúrgica em instituições públicas e privadas no Brasil

\begin{tabular}{lll}
\hline Média instituição púbica (h) & Média instituição privada(h) & Média geral (h) \\
\hline 3800,11 & 3916,11 & 3963,67 \\
\hline
\end{tabular}

Fonte: Elaborado pelos autores.

A diferença entre a média das cargas horárias das instituições públicas e privadas é de aproximadamente 116 horas. Esse contraste representa cerca de $3 \%$ da média total do curso. A otimização da grade curricular do curso é um dos fatores a serem trabalhados nas instituições públicas e privadas, tornando as disciplinas mais direcionadas para o aumento da qualidade da formação, e reduzindo a carga horária.

\subsection{Fundação dos cursos de Engenharia Metalúrgica no Brasil}

A maioria das instituições privadas do Brasil foram criadas a partir dos anos 2000 (Gráfico 4), sendo a Pontifícia Universidade Católica do Rio de Janeiro a única instituição privada criada antes de 2000 e regulamentada pelo MEC. O crescimento dos cursos de Engenharia Metalúrgica regulamentados nas instituições privadas está diretamente relacionado ao crescimento do PIB do Brasileiro, devido ao aumento da demanda por profissionais da área (IBGE, 2019). No período de 2010 a 2019, é considerável o aumento da criação de instituições públicas, sendo a década com maior criação desse tipo de instituição. Segundo Gusso e Nascimento (2011), o número médio de engenheiros metalurgistas e de materiais empregados em 2009 era 4.304, com uma taxa de crescimento do emprego de 3,6\%, em média, no período de 2004 a 2009, justificando a intensa criação de cursos de Engenharia Metalúrgica no período de 2000 a 2009. Vale ressaltar que o curso da Universidade Federal de Ouro Preto foi computado como criado em 1969, devido à incorporação da Escola de Minas à instituição, como citado na introdução do presente trabalho. 
Gráfico 4 - Criação dos cursos de Engenharia Metalúrgica

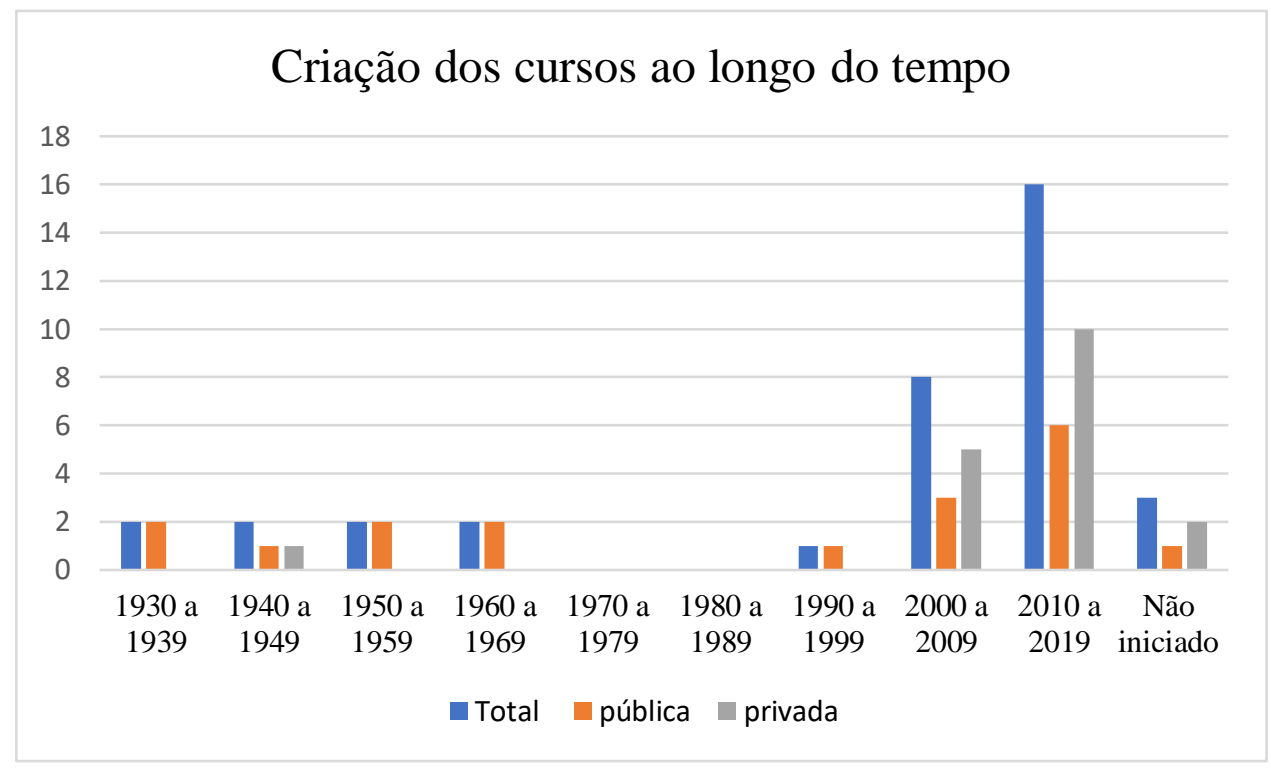

Fonte: Elaborado pelos autores.

\subsection{Atual situação dos cursos de Engenharia Metalúrgica no Brasil}

Das 36 instituições regulamentadas pelo MEC, 78\% estão em normal funcionamento, conforme apresenta a Gráfico 5. PUC-RIO, UVV, Faculdade Estácio-Belém, Faculdade Pitágoras-Betim e a Faculdade Pitágoras unidade Contagem são as cinco instituições com os cursos em processo de extinção no Brasil. Todas essas são instituições privadas de ensino, o que era esperado, já que a falta de alunos pode justificar esse fato, visto que instituições privadas dependem da demanda de estudantes para custear a manutenção de cursos onerosos, como de Engenharia Metalúrgica. Entre essas instituições, a Faculdade Estácio de Belém chama a atenção por ser a única do estado do Pará, região onde encontra-se um dos polos metalúrgicos brasileiros, a Serra de Carajás.

A grande evasão nos cursos de Engenharia Metalúrgica é outro favor que influencia fortemente na extinção dos cursos. Após a reformulação do Enem, em 2009, grande parte das instituições de ensino, principalmente as públicas, abandonaram o sistema de vestibular próprio e adotaram o SiSU como sistema de seleção. Segundo Maria José Sena, reitora da UFRPE em 2014, a implantação do SiSU teve grande influência na evasão nas instituições, uma vez que o modelo de seleção permite aos estudantes escolherem o curso pelas notas, e não pela vocação (COLÉGIO UNICO, 2014).

A crise econômica que assola o Brasil há alguns anos causa a diminuição da demanda por engenheiros metalurgistas. Apesar da diminuição dessa demanda, CEFET/MG, FAMA e UNIFEMM são as três instituições já autorizadas pelo MEC para o início da operação do curso. 
Gráfico 5 - Situação das instituições brasileiras que oferecem o curso de Engenharia Metalúrgica

\section{Situação das instituições país}

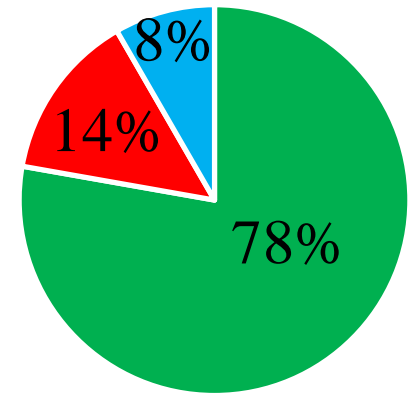

- Em funcionamento - Em Extinção - Não inciado

Fonte: Elaborado pelos autores.

\section{7 Índices de avaliação do MEC}

O Exame Nacional de Desempenho dos Estudantes (Enade) é o método de avaliação utilizado pelo MEC para avaliar os cursos de ensino superior. Analisando da Gráfico 6 podemos concluir que a avaliação das instituições privadas cresceu ao longo dos anos, atingido o seu ápice no ano de 2017. A média de avaliação das instituições públicas tiveram uma pequena variação, atingindo a média 4 no ano de 2011.

Gráfico 6 - Resultado de avaliações do Enade dos cursos de Engenharia Metalúrgica de instituições de ensino brasileiras no período de 2005 a 2017

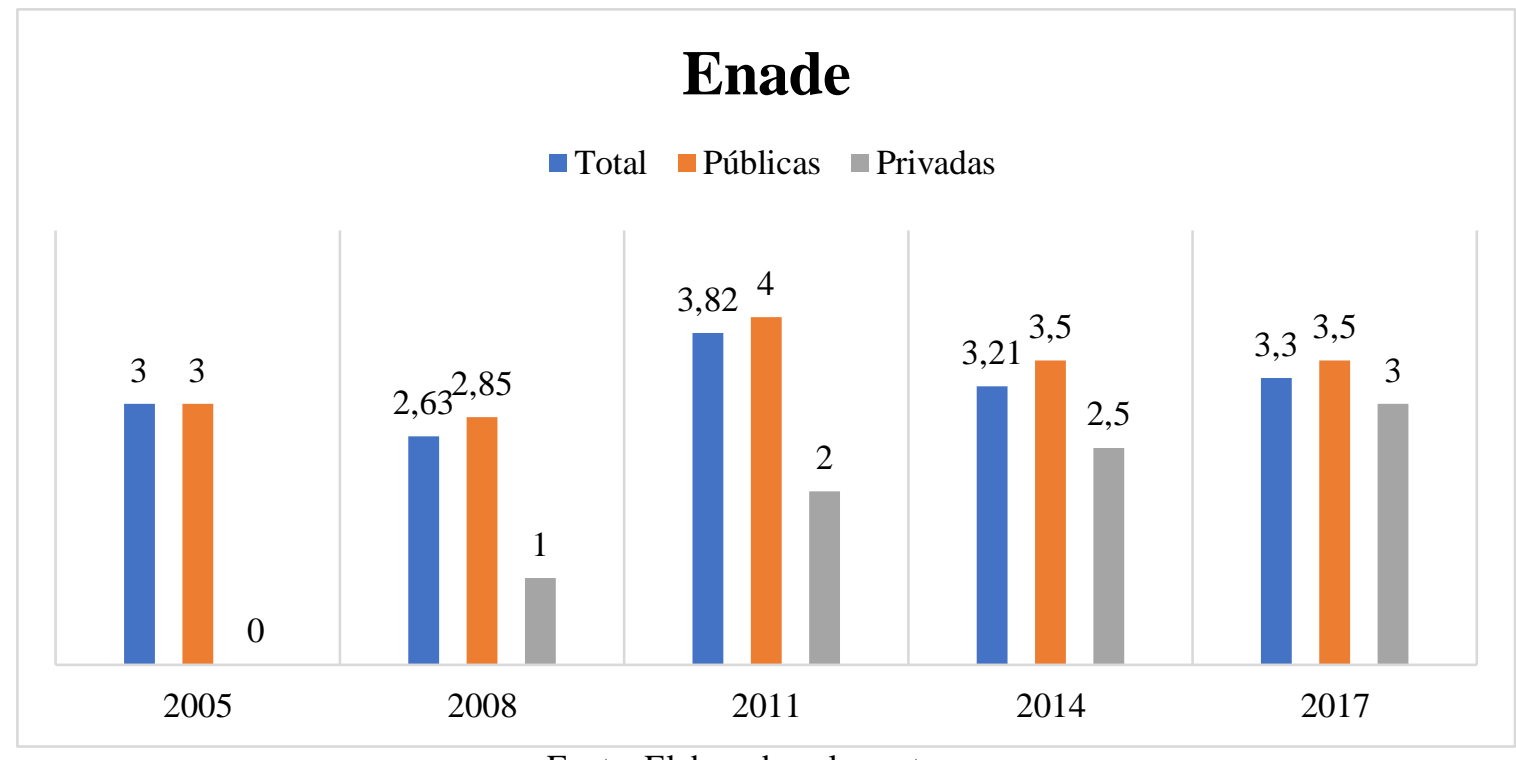

Fonte: Elaborado pelos autores.

A avaliação dos dados do portal e-MEC indica que as instituições que conseguiram atingir a nota máxima no Enade foram a Universidade Federal de Ouro Preto (2011), 
Universidade Federal de Minas Gerais (2014), Universidade Federal do Rio de Janeiro (2005), Instituto Militar de Engenharia (2011, 2014 e 2017) e o Instituto Federal de Educação, Ciência e Tecnologia do Espirito Santo (2011). Apesar da média crescente das instituições privadas, as instituições públicas sempre tiveram média superior à das instituições privadas. Outro importante parâmetro a ser observado é que a média das instituições públicas sempre foi superior ou igual à média total.

\section{CONCLUSÃO}

Com base nos dados estudados referentes aos cursos de Engenharia Metalúrgica oferecidos pelas instituições brasileiras, observa-se que o curso pode ser otimizado. Conclui-se que a disponibilidade dos cursos está diretamente relacionada à localização e à demanda de profissionais da área, justificada pelo número significativo de cursos em extinção no país.

Observa-se ainda que o curso de Engenharia Metalúrgica é um curso que exige considerável investimento para a manutenção, tornando insustentável a operação do curso com a queda da demanda de alunos. Prova disso é o equilíbrio entre o número de instituições públicas e privadas no Brasil, já que para a implementação do curso de Engenharia Metalúrgica por uma instituição privada, deve-se ter uma demanda considerável de alunos para manutenção do curso.

Em relação ao tipo de instituição, é notório que os cursos públicos são mais bem avaliados, mas é necessário ressaltar a evolução da média de avaliação dos cursos em instituições privadas por meio do Enade ao longo dos anos.

\section{Agradecimentos}

Os autores agradecem à UFOP pelo apoio na realização deste trabalho.

\section{Referências}

BARROS, G. O desenvolvimento do setor siderúrgico brasileiro entre 1900 e 1940:

Crescimento e substituição de importações. Estud. Econ., São Paulo, v. 45, n. 1, p. 30, Março 2015.

COLÉGIO ÚNICO. EVASÃO NA UFRPE AUMENTA COM O SISU. Colégio Único, 2014. Disponivel em: <http://www.colegiounico.com.br/noticias/ler-noticia/id/443>. Acesso em: 24 maio 2020.

ESCOLA DE MINAS. História da Escola de Minas. Escola de Minas - Universidade Federal de Ouro Preto, 2018. Disponível em: 〈https://www.em.ufop.br/index.php/historia〉. Acesso em: 17 maio 2020.

\section{GUSSO, D. A.; NASCIMENTO, P. A. M. Contexto e dimensionamento da formação de} Pessoal técnico-científico e de engenheiros. Radar, Brasília: Ipea, n. 12, p. 23-33. Fev. 2011.

IBGE. Séries históricas. IBGE, 2019. Disponível em:

$<$ https://www.ibge.gov.br/estatisticas/economicas/contas-nacionais/9300-contas-nacionaistrimestrais.html? $=\& \mathrm{t}=$ series-

historicas\&utm_source=landing\&utm_medium=explica\&utm_campaign=pib\#evolucaotaxa>. Acesso em: 15 maio 2020. 
LANDGRAF, F. J. G.; TSCHIPTSCHIN, A. P.; GOLDENSTEIN, H. Notas sobre a história da metalurgia no Brasil (1500-1850). História técnica e da tecnologia no Brasil, São Paulo, 1994. 412.

MARCOLIN, N. Os primeiros anos da siderurgia. Pesquisa FAPESP, São Paulo, v. n.i, n. 173, p. n.i, julho 2010.

MOTA, A. C. F. V. Pólos minero-siderúrgicos no Brasil: a contribuição da avaliação ambiental estratégica no caso de Corumbá. COPPE/UFRJ. Rio de Janeiro, p. 162. 2009.

RODACOSKI, M.R. e TOZZI, M. A educação superior privada é moral? Anais: XXXVI Congresso Brasileiro de Educação em Engenharia. São Paulo - SP. 2008

SALES , F. D. L. O desenvolvimento econômico de Caxias do Sul na perspectiva do acervo do Museu Municipal. Faculdade Integrada de Pernambuco. Pernambuco, p. 13. 2006.

\section{ACTUAL SITUATION OF METALLURGICAL ENGINEERING COURSE IN BRAZIL}

Abstract: This present work carried out a study of the actual situation of the Metallurgical Engineering course in Brazil based on data available through the e-MEC registry. The parameters analyzed during this work were: the availability of the courses in the national territory; number of vacancies; academic load; courses history; operating situation; and MEC evaluation indexes. Starting from these analyzes, it was possible to identify the real situation of the courses in Brazil, concluding that the course can be optimized. Among the conclusions presented, we can highlight the relation between the location and demand for professionals with the availability of the course, and the balance between the number of public and private institutions. It is also worth mentioning the superiority of public courses in relation to private courses at Enade, and the growing average of private institutions in the exam over the years.

Keywords: Metallurgical Engineering. Courses. Metallurgical centers. 